\title{
Do new ways of working increase informal learning at work?
}

Citation for published version (APA):

Gerards, R., de Grip, A., \& Weustink, A. (2021). Do new ways of working increase informal learning at work? Personnel Review, 50(4), 1200-1215. https://doi.org/10.1108/PR-10-2019-0549

Document status and date:

Published: 22/06/2021

DOI:

10.1108/PR-10-2019-0549

Document Version:

Accepted author manuscript (Peer reviewed / editorial board version)

Document license:

CC BY-NC

\section{Please check the document version of this publication:}

- A submitted manuscript is the version of the article upon submission and before peer-review. There can be important differences between the submitted version and the official published version of record.

People interested in the research are advised to contact the author for the final version of the publication, or visit the DOI to the publisher's website.

- The final author version and the galley proof are versions of the publication after peer review.

- The final published version features the final layout of the paper including the volume, issue and page numbers.

Link to publication

\footnotetext{
General rights rights.

- You may freely distribute the URL identifying the publication in the public portal. please follow below link for the End User Agreement:

www.umlib.nl/taverne-license

Take down policy

If you believe that this document breaches copyright please contact us at:

repository@maastrichtuniversity.nl

providing details and we will investigate your claim.
}

Copyright and moral rights for the publications made accessible in the public portal are retained by the authors and/or other copyright owners and it is a condition of accessing publications that users recognise and abide by the legal requirements associated with these

- Users may download and print one copy of any publication from the public portal for the purpose of private study or research.

- You may not further distribute the material or use it for any profit-making activity or commercial gain

If the publication is distributed under the terms of Article $25 \mathrm{fa}$ of the Dutch Copyright Act, indicated by the "Taverne" license above, 


\title{
Do New Ways of Working increase informal learning at work?
}

Ruud Gerards, Andries de Grip and Arnoud Weustink

\section{Ruud Gerards}

Research Centre for Education and the Labour Market (ROA), Maastricht University; e-mail:

R.Gerards@maastrichtuniversity.nl; ROA, Maastricht University, Netherlands, P.O. Box 616, NL-6200 MD Maastricht, The Netherlands; phone +31 43 3883647; fax +31 433884914.

Full CV: https://roa.maastrichtuniversity.nl/r.gerards

Orcid ID: https://orcid.org/0000-0001-7570-8298

\section{Andries de Grip}

Research Centre for Education and the Labour Market (ROA), Maastricht University, Netherlands and IZA, Bonn, Germany; e-mail: A.deGrip@maastrichtuniversity.nl; ROA, P.O. Box 616, NL-6200 MD Maastricht, The Netherlands; phone +31 43 3883647; fax +31 43 3884914 .

Full CV: https://roa.maastrichtuniversity.nl/a.degrip

\author{
Arnoud Weustink \\ Alumnus School of Business and Economics, Maastricht University, Netherlands; e-mail: \\ a.weustink@alumni.maastrichtuniversity.nl; P.O. Box 616, NL-6200 MD Maastricht, The \\ Netherlands.
}

\section{Acknowledgements}

We thank Simon Beausaert and Sanne van Wetten for their valuable comments and suggestions, and Evert Webers of Etil Research Group for facilitating the fieldwork. We also thank participants of the EURAM 2018 conference, the 2019 International conference of the Dutch HRM Network, the Universitat de les Illes Balears Business Economics Seminar, the James Cook University College of Business, Law and Governance seminar, the Maastricht University Learning \& Work seminar, and the ROA poster session for their helpful remarks and questions. 
This research did not receive any specific grant from funding agencies in the public, commercial, or not-for-profit sectors.

\section{Abstract}

Purpose - The purpose of this paper is to provide a first investigation of how New Ways of Working (NWW) and its various facets relate to employee informal learning at work, while accounting for a range of known antecedents of informal learning.

Design/methodology/approach- The Job Demand-Control model and the Job DemandsResources model underpin our hypotheses on how NWW would relate to informal learning. The hypotheses are tested using the Preacher and Hayes (2008) bootstrap method for mediation analysis, accounting for the potential mediating effect of the frequency with which employees receive feedback.

Findings- The analyses show that NWW positively relate to informal learning at work. This relation is mediated by the frequency with which employees receive feedback. Further analysis shows that one particular NWW facet - access to organizational knowledge - is an independent driver of informal learning, hardly mediated by receiving feedback.

Practical implications- The results suggest that managers who seek new ways to stimulate informal learning can do so by giving their employees more access to organizational knowledge, for instance, by leveraging the potential of modern ICT.

Originality/value - This empirical paper is the first study on the impact of NWW on informal learning at work. Using data on the Dutch working population, it provides novel insights for several strands of literature as well as for practitioners.

Keywords new ways of working, informal learning, feedback, mediation analysis

Paper type Research paper 


\section{Introduction}

Fueled by ongoing globalization and advances in information and communication technologies, the current knowledge-based economy demands the continuous adaptation of management and organization practices for organizations to remain competitive in their sales markets, as well as in the labor market. This has led to much scholarly interest in 1) the accompanying changes in human resource management practices (Laursen and Foss, 2003), 2) informal learning in the workplace as a key instrument in keeping workers' skills up-to-date with changes in job content (Noe et al., 2013; De Grip, 2015), and 3) changes in the organization of work that build on the opportunities created by information and communication technologies, such as the proliferation of teleworking due to affordable mobile connections (Allen et al., 2015) and the introduction of more individualized employment relations (e.g. De Leede et al., 2004). Due to the tendency for such new practices to be adopted in bundles (Laursen and Mahnke, 2001), the concept of new ways of working (NWW) has emerged (Peters et al., 2014). Gerards et al. (2018) define NWW as consisting of five facets: 1) time- and location-independent work, 2) management of output, 3) access to organizational knowledge, 4) flexibility in working relations, and 5) freely accessible open workplaces. Due to the Covid-19 regulations in many countries, increasing our insights into the impact of NWW on informal learning has even become more important as in these countries most office workers have to work at home.

This paper is a first investigation into the relation between the changes in work organization and human resource management practices bundled into NWW and informal learning in the workplace. Gerards et al. (2018) note that various facets of NWW increase workers' autonomy in their job, which is a known driver of informal learning (e.g. Van Ruysseveldt and Van Dijke, 2011). This suggests that we might expect NWW to relate positively 
to informal learning. However, several studies on teleworking, which comprises the first three facets of NWW, report negative effects of teleworking on informal learning (Kurland and Bailey, 1999; Cooper and Kurland, 2002) and on related outcomes such as information exchange frequency (Fonner and Roloff, 2010), and knowledge sharing (Allen et al., 2015). This suggests that NWW may relate negatively to informal learning, which seems to contrast the expectations related to the increase of worker autonomy. Therefore, we see it as our main goal to shed a first and clarifying empirical light on the relation between NWW and informal learning and intend to provide stepping-stones for future research to build on. To achieve this, we will first investigate the relation between NWW as one bundled variable and informal learning broadly defined. In addition, we will further explore the relations between on the one hand the five specific NWW facets and on the other hand informal learning broadly defined, as well as specifically focusing on learning from colleagues and supervisors.

As various studies show that informal learning is fostered by the availability of feedback (e.g. Schürmann and Beausaert, 2016; Cerasoli et al., 2018) and that, in turn, feedback is affected by contextual variables such as NWW (e.g. Steelman et al., 2004; Anseel et al., 2015), we include the frequency of receiving feedback as mediator.

Our paper connects various fields of research and makes several contributions to them. First, our research question relates the literature on NWW to the literature on informal learning in the workplace. Specifically, we extend the literature on the antecedents of informal learning with drivers that are related to major developments in many organizations, such as time- and locationindependent work, management of output, access to organizational knowledge, and open workplaces. Second, we contribute to the emerging literature on the effects of NWW on employee outcomes such as work engagement (Ten Brummelhuis et al., 2012; Gerards et al., 2018), employee performance (De Leede and Kraijenbrink, 2014), work-related flow (Peters et 
al., 2014), and productivity and organizational commitment (De Leede and Heuver, 2017). Third, we are the first to explicitly link the NWW context to the frequency of receiving feedback. Fourth, in doing so, we also contribute to the literature on the effects of teleworking on workplace outcomes, as well as the literature on the feedback environment (e.g. Steelman $e t$ al., 2004). In the latter, the antecedents of the feedback environment have been understudied (Dahling et al., 2017) and the frequency of receiving feedback is a key facet (Steelman et al., 2004).

\section{NWW, receiving feedback, and informal learning}

$N W W$

NWW are a phenomenon that bundles various human resource management practices such as management of output, teleworking, and flexibility in time and location of work. Several definitions of NWW exist in the literature, disentangling NWW into three to five facets, usually including at least an element of teleworking and management of output (e.g. De Leede and Kraijenbrink, 2014; Peters et al., 2014). We follow Gerards et al. (2018) who disentangle NWW into five facets: 1) time- and location-independent work, 2) management of output, 3) access to organizational knowledge, 4) flexibility in working relations, and 5) a freely accessible open workplace. We now briefly explain these five facets and refer to Gerards et al. (2018) for more details.

Time- and location-independent work refers to working independently of time and place. Management of output or performance allows workers themselves to determine the way they work. Access to organizational knowledge refers to free access to and use of organizational knowledge, experience, and ideas, for instance, via the use of tablets, smartphones, or PCs, and 
by quickly being able to reach colleagues and managers. Flexibility in working relations refers to practices that accommodate employees' working life such that it fits their private situation and preferences. Finally, a freely accessible open workplace refers to refurbishing offices into freely accessible open workplaces to minimize physical and mental distance to stimulate collaboration.

\section{Informal learning}

The literature on informal learning and workplace learning, particularly in the fields of career development, education and labor economics, focuses on 1) "learning by doing," 2) learning from non-interpersonal sources (such as reading professional or academic literature) and 3) learning from peers and supervisors (e.g. Noe et al., 2013; De Grip et al., 2016; Tews et al., 2017).

Several studies show that informal learning accounts for most of the learning in organizations (e.g. De Grip, 2015). Marsick and Watkins (2001, p. 28) define informal learning as learning that happens "wherever people have the need, motivation and opportunity for learning." In their metastudy on informal learning behaviors, Cerasoli et al. (2018) discuss various drivers of informal learning under the headings of demographics, individual predispositions, and situational antecedents. Most other studies focus on a single group of antecedents of informal learning. For instance, Noe et al. (2013) focus on individual predispositions such as personality traits, whereas others focus on situational antecedents such as the workplace learning culture, access to resources, and peer and supervisor support (e.g. Kyndt et al., 2009; De Grip et al., 2016; Tews et al., 2017). A common finding across these studies is that learning from peers and supervisors is fostered by receiving feedback (e.g. Schürmann and Beausaert, 2016; Cerasoli et al., 2018).

The management development and job design literature also studies informal learning, under the headers 'on-the-job learning' and 'learning from work experiences'. From this literature we know that challenging situations and assignments stimulate on-the-job learning (e.g. 
McCauley et al., 1994; Preenen et al., 2011). As an elaborate discussion of the contributions of all these strands of literatures to our knowledge on informal learning is beyond the scope of our paper, we here refer to two review studies that include insights from several of the above strands of literatures (Bell et al., 2017; Clardy, 2018).

The empirical and theoretical relations between New Ways of Working and informal learning

Although no earlier research explicitly studies the relation between NWW and informal learning, a number of studies that investigate NWW in relation to outcome variables closely related to informal learning can help in forming expectations about the relation between NWW and informal learning. In a case study of 73 employees in a Dutch organization, Blok et al. (2012) find that NWW reduce knowledge sharing. Moreover, numerous studies relate one or more individual facets of NWW to informal learning or related variables. Several studies on teleworking, which can be considered a subset of NWW comprising the first three facets of NWW, report negative effects of teleworking on informal learning (Kurland and Bailey, 1999; Cooper and Kurland, 2002), information exchange frequency (Fonner and Roloff, 2010), and knowledge sharing (Allen et al., 2015). To quote one example: "The private sector managers complained that telecommuters missed out on these learning opportunities because team members often learned from one another informally" (Cooper and Kurland, 2002, p. 521). From these studies one might expect that the changes in communication method and reduction in office presence due to NWW negatively affect informal learning. In contrast, De Leede and Kraijenbrink (2014) find that workers' autonomy with regard to their work schedule and location positively affects trust in colleagues and leaders, and social cohesion, as measured, for example, with informal learning-related items such as feedback and co-workers helping each other. 
However, apart from these contradicting empirical pieces of evidence, there are several theories that can help form expectations about the relation between NWW and informal learning. The Job Demand-Control model (Karasek, 1979) has been extensively used in occupational health psychology (e.g. Van der Doef and Maes, 1999; De Lange et al., 2003), to study how variations in job demands and job control explain variations in job stress. It argues that job stress or strain is highest when job demands are high and job control is low, and vice versa. Interestingly for our paper, the Job Demand-Control model has also been used to relate differences in job demands and control to outcomes other than job stress, namely workplace learning-oriented outcomes (e.g. Bond and Flaxman, 2006; Van Ruysseveldt and Van Dijke, 2011). The active learning hypothesis - which originates from the Job Demand-Control model stated that those in jobs with high levels of both demands and control would exhibit high levels of learning (Karasek and Theorell, 1990). Although empirical evidence on this hypothesis is mixed (Van Ruysseveldt and Van Dijke, 2011), most studies find better learning outcomes for jobs with high levels of control (or autonomy). As NWW increase job control and autonomy (Ten Brummelhuis et al., 2012; Peters et al., 2014; Gerards et al., 2018), we expect on the basis of the Job Demand-Control model that NWW positively relate to informal learning.

Gerards et al. (2018) and Peters et al. (2014) combine insights on the effects of the various facets of NWW with those of the Job Demands-Resources (JD-R) model (Bakker and Demerouti, 2007) to explain the mechanisms affecting, respectively, work engagement and "work-related flow." Similarly, the JD-R model can also be used to relate NWW to informal learning, highlighting that job demands may be stressors while job resources may be motivators for informal learning. Peters et al. (2014) reason that NWW induce important resources at the job level, and at the interpersonal level. For instance, all facets of NWW increase job autonomy 
(Gerards et al., 2018), which is found to relate positively to informal learning (e.g. Schürmann and Beausaert, 2016; Cerasoli et al., 2018). The limited empirical evidence, that only connects NWW and informal learning relatively loosely, does not suffice to form clear expectations on the relation between NWW and informal learning. It certainly does not suffice to form separate expectations for the relation between each of the five NWW facets and informal learning. Therefore, we base our first hypothesis on the two theoretical models that are used in the related literatures. Both the Job Demand-Control and the JD-R model point towards a positive relation between NWW and informal learning. This is strongly based on the knowledge that all facets of NWW entail increased autonomy and that autonomy in both models predicts positive outcomes. However, also the two theoretical models do not suffice to form separate expectations for the five facets of NWW in relation to informal learning. Therefore, our first hypothesis is formulated regarding NWW as a bundled variable:

H1: $\quad$ NWW relate positively to informal learning. However, as this is the first study on the relation between NWW and informal learning, we will also further explore how the five facets of NWW relate to informal learning, without a priori forming expectations about these.

\section{Frequency of receiving feedback as a mediator}

The importance of feedback for informal learning is well established in the literature (e.g. Eraut, 2004). Theoretically, feedback stimulates reflection (Noe et al., 2013) and needs processing, which both consist of informal learning activities (Mulder, 2013). Moreover, in terms of the JD-R model, feedback is a job resource that is empirically shown to have a positive effect on informal 
learning (e.g. Nelen and De Grip, 2009; Mulder, 2013; Schürmann and Beausaert, 2016; Cerasoli et al., 2018).

For feedback to mediate between NWW and informal learning, NWW should also affect feedback. The literature on feedback is unambiguous about the fact that contextual variables influence feedback (e.g. Steelman et al., 2004; Anseel et al., 2015). Although no studies explicitly link NWW to the frequency of receiving feedback, various studies find that NWW affect variables included in the feedback environment scale (FES; Steelman et al., 2004) and/or the quality of leader-member exchange (LMX; e.g. Gerstner and Day, 1997).

Peters et al. (2014) reason that NWW stimulate key resources at the interpersonal level, such as the supportive behavior of line managers and colleagues, which enhances LMX quality and thus the feedback environment. De Leede and Kraijenbrink (2014) find that NWW positively affect trust and social cohesion, which they measured amongst others with items on feedback. Moreover, Ten Brummelhuis et al. (2012) find that NWW positively affect effective and efficient communication, which relates to the source availability facet of the FES.

Furthermore, several studies on flexible work designs and teleworking touch upon the relation between one or more facets of NWW and facets of the feedback environment and/or LMX quality. Most underscore the negative effects of such work designs on the FES facet frequency of receiving feedback (e.g. Sardeshmukh et al., 2012; Boell et al., 2016) or on the LMX quality (e.g. Cooper and Kurland, 2002). An exception is Caillier (2013), who does not find a significant relation between telecommuting and the frequency of receiving feedback.

Related to the NWW facet flexibility in working relations, Branine (2003) finds that job sharers note the transfer of expertise and knowledge as an advantage of their flexible arrangement, as well as the mutual support they receive from each other, which relates to the 
source credibility facet of the FES. Likewise, Kossek and Lee (2008) argue that reduced-load work (i.e., a form of part-time work) improves communication and relations between co-workers. With regard to the minimized physical and mental distance in the work place, which is the intent of the freely accessible open workplace NWW facet, the social relations approach predicts that this minimized distance should enhance feedback whereas the sociotechnical perspective predicts that the open workspace hampers feedback due to the reduced privacy (Oldham and Brass, 1979). Empirical studies that explicitly analyze the effect of open workplaces on feedback find mixed results (e.g. Oldham and Brass, 1979; Pejtersen et al., 2006). Based on the above literature, we hypothesize that the frequency of receiving feedback mediates the relationship between NWW facets and informal learning, without formulating expectations regarding the sign of the effect:

H2: $\quad$ The frequency of receiving feedback mediates the relation between NWW and informal learning.

Figure 1 shows the hypothesized relations between NWW and informal learning.

<Insert Figure 1 about here>

\section{Control variables}

Building on the methodological guidance of Spector and Brannick (2011), we do not include all potential control variables at our disposal in our analyses, but merely those that are known antecedents of informal learning and for which we can thus form expectations. We use the meta study by Cerasoli et al. (2018) on informal learning behaviors as the basis for our choice of control variables. They distinguish personal antecedents and situational antecedents of informal learning, whereby the former are further broken down into the clusters 'demographics' and 
'individual predispositions', and the latter are broken down into the clusters 'job/task characteristics', 'support', and 'learning opportunities'.

We now list our control variables and add in brackets in what direction we expect each to relate to informal learning, according to Cerasoli et al. (2018). Of the personal antecedents, we include from the demographics cluster, age (-), education (+), gender (- for males), tenure (+), job tenure (+), marital status (+ for being in a couple), and from the individual predispositions cluster we include intrinsic work motivation (which may also translate into learning motivation and is expected to positively affect informal learning). Of the situational antecedents we include from the job/tasks characteristics cluster the percentage of working time being involved in teamwork $(+)$, from the support cluster the amount of organizational learning support received (+), and from the learning opportunities cluster the respondents' recent formal training participation $(+)$.

\section{Data and methodology}

Our data stem from a survey among Dutch households collected by Etil Research Group ${ }^{\mathrm{i}}$. The survey was a follow-up to the survey in June 2013 used to gather the data on NWW used in Gerards et al. (2018). In April 2015, the questionnaire was sent to the 1,007 respondents (including those who partially responded) to the earlier survey. ${ }^{\text {ii }}$ This resulted in 762 responses. To focus on employees only, we excluded 45 entrepreneurs. Further, we excluded 75 respondents who stated not working in a building (e.g. truck and train drivers, delivery workers), because the fifth NWW facet regarding a freely accessible open workplace does not refer to these workers. This resulted in an estimation sample of 642 employees from a broad variety of occupational fields and sectors. 
To measure informal learning, we use the three-statement version of the Programme for the International Assessment of Adult Competencies (PIAAC) survey (OECD, 2014). The respondents were asked to rate the statements on a five-point scale, from "never" to "every day." The items are "In your job, how often do you learn new work-related things from co-workers or supervisors?", "How often does your job involve learning-by-doing from the tasks you perform?" and "How often does your job involve keeping up to date with new products and services?" $(\alpha=$ $0.80)$.

To measure the degree to which employees experience NWW, we use the 10 items from Gerards et al. (2018) that compose the five NWW facets. An example item is "I am able to determine where I work." These items are rated on a five-point scale from "not at all" to "to a very high degree." $(\alpha=0.81){ }^{\mathrm{iii}}$

Building on various studies (e.g. Morran and Stockton, 1980; Steelman et al., 2004; Nelen and De Grip, 2009), we construct our measure for the frequency of receiving feedback from four items, distinguishing between positive and critical feedback. These items, derived from Nelen and De Grip (2009) and Steelman et al. (2004), measure the frequency with which respondents receive positive and/or critical feedback from their co-workers and supervisors on a seven-point scale ranging from "never" to "always". Example items are "How often does your supervisor give you positive feedback after successfully completing a task?" and "How often do your coworkers tell you how you can improve your performance?" $(\alpha=0.80)$.

We measure our control variables as follows: gender using the usual dummy variable, age is categorized in three groups: $<35,35-50$, and 50+ and education into five groups whereby on the highest levels we distinguish bachelor from master degrees. Tenure, job tenure and the percentage of time respondents work in teams are measured as continuous variables. Marital status is proxied by a dummy variable indicating 1 if the individual is part of a couple, and 0 
otherwise. We measure intrinsic work motivation $(\alpha=0.89)$ using the three item construct of the Multidimensional Work Motivation Scale (Gagné et al., 2015). An example item is "Because the work I do is interesting" (with the stem being "Why do you or would you put efforts into your current job?” (Gagné et al., 2015, p. 196). Our measure for organizational learning support consists of nine $0=\mathrm{no} / 1=$ yes items on whether various human resource practices were used for the respondent. These practices include e.g. training, performance appraisal, personal development plan, and coaching. The nine items were summed and subsequently standardized to a mean of zero and a standard deviation of one. We control for recent formal training participation using a dummy variable indicating 1 if respondents have participated in training in the 12 months preceding the survey or were participating at the time of the survey, and 0 otherwise.

Table I shows both the Cronbach alpha coefficient for the NWW facets and the correlations between NWW (both the bundled variable and the separate facets), informal learning, and the frequency of receiving feedback. All NWW facets, except management of output, appear to be significantly correlated to informal learning, whereby access to organizational knowledge shows the strongest correlation to informal learning. Furthermore, the frequency of receiving feedback is significantly correlated with informal learning, NWW as a bundle, and all individual facets of NWW. The Cronbach alphas show that all variables are internally consistent. ${ }^{\text {iv }}$ Furthermore, we perform factor analysis based on a polychoric correlation matrix on the latent constructs of informal learning, feedback, and the multi-itemed NWW facets time- and location-independent work, access to organizational knowledge, and a freely accessible open workplace which all show only one item has an eigenvalue above one and all have adequate to strong factor loadings. ${ }^{\mathrm{v}}$ We calculated the total scale scores of each of these variables by means of regression scoring, and subsequently standardized the scores. 
<Insert Table 1 about here>

\section{Results}

\section{Main results}

First, we test a mediation model with the bundled NWW variable as the independent variable. Following Gerards et al. (2018), we use the Preacher-Hayes (2008) bootstrap method for mediation analysis, which uses ordinary least squares regressions to estimate the coefficients of all direct relations in our model $\left(a_{i}, b_{i}\right.$, and $\left.c^{\prime}\right)$, followed by bootstrapping to determine the significance of the indirect and total effects.

Figure 2 shows that NWW as a bundle have a significant positive total effect on informal learning $(\beta=0.11)$. Moreover, NWW are significantly positively related to the mediator feedback frequency $(\beta=0.26)$. In turn, the frequency of receiving feedback is highly significant positively related to informal learning $(\beta=0.25)$. When taking account of the mediating effect of the frequency of receiving feedback $(\beta=0.07)$, no significant direct relation between NWW and informal learning remains. ${ }^{\text {vi }}$ Hence, the relation between NWW as a bundle and informal learning is positive, but fully mediated by the frequency of receiving feedback, providing confirmation for both hypotheses 1 and 2 .

Of our control variables, intrinsic work motivation, recent formal training participation, the percentage of time performing teamwork, and organizational learning support all show the expected significantly positive relation to informal learning. Also, as expected, those with a master degree report significantly more informal learning compared to those with lower levels of education, and those age 50+ show significantly lower levels of informal learning than younger cohorts. However, we find no significant effects from our remaining control variables career 
tenure, job tenure and marital status. Our total model is highly significant $(p<0.001)$ and explains 37 percent of the variance in informal learning.

<Insert Figure 2 about here>

\section{Additional analysis distinguishing five NWW facets}

To better understand the drivers of the relationship between NWW and informal learning, we test a mediation model that includes the five separate NWW facets as independent variables, again applying the Preacher-Hayes (2008) method and the same controls as before. Figure 3 summarizes the results of this analysis. The NWW facet access to organizational knowledge is the only facet with a strong significant total effect $(\beta=0.12)$ on informal learning. The facet flexibility in working relations has a weakly significant total effect on informal learning $(\beta=$ 0.07). However, we see significant relations between the facets access to organizational knowledge, flexibility in working relations, and a freely accessible open workplace and the mediator feedback frequency $(\beta=0.11, \beta=0.14$, and $\beta=0.10$, respectively). Further, the mediating variable feedback frequency is highly significantly $(\beta=0.24)$ related to informal learning.

The specific indirect effects of the five facets of NWW on informal learning that run via the mediator are shown in parentheses and the direct effects after accounting for mediation are shown in brackets in Figure 3. When taking account of the mediation, the direct effect of access to organizational knowledge $(\beta=0.09)$ on informal learning drops somewhat, as is shown by the magnitude of the coefficient, and remains significant. Hence, this effect is mediated by the frequency of receiving feedback only to a limited extent, with the indirect effect modest in magnitude $(\beta=0.03)$. The direct effect of flexibility in working relations $(\beta=0.04)$ is insignificant. Hence, the relation of this facet and informal learning is fully mediated by the 
frequency of receiving feedback and results in a significant indirect effect of $(\beta=0.03)$. The last effect on informal learning comes from the facet a freely accessible open workplace and is only indirect $(\beta=0.03)$. The total model is again highly significant $(p<0.001)$ and explains 37 percent of the variance in informal learning. The effects of our control variables are the same as found for our first model with NWW as a bundle.

<Insert Figure 3 about here>

Additional analysis focusing on learning from colleagues and supervisors.

In our main analysis, we measured informal learning by the three-statement version of the PIAAC survey (OECD, 2014). However, two of the items-"How often does your job involve learning-by-doing from the tasks you perform?" and "How often does your job involve keeping up-to-date with new products and services?"-refer to learning by doing and therefore do not directly relate to our mediating variable feedback as the third item- "In your job, how often do you learn new work-related things from co-workers or supervisors?" Therefore, we might expect that the mediating role of the frequency of receiving feedback would increase in magnitude when we focus on learning from colleagues and supervisors only.

Figure 4 shows the results when we focus on learning from colleagues and supervisors. As expected, the figure shows a slightly stronger relation between the frequency of receiving feedback and informal learning from colleagues and supervisors $(\beta=0.28)$, compared to $\beta=0.24$ in Figure 3 when using the broader definition of informal learning. Concomitantly, the total indirect effect also increases slightly, from 0.09 (see Figure 3) to 0.11. More interestingly, apart from the positive effects of the facets access to organizational knowledge $(\beta=0.13)$ and flexibility in working relations $(\beta=0.09)$, we now find an additional facet of NWW that directly 
affects informal learning from colleagues and supervisors: Management of output negatively relates to informal learning from colleagues and supervisors $(\beta=-0.11)$. When accounting for the mediating effect of the frequency of receiving feedback, only management of output $(\beta=-$ $0.10)$ and access to organizational knowledge $(\beta=0.10)$ remain significantly directly related to informal learning from colleagues and supervisors. Their coefficients have hardly decreased. The total model is again highly significant $(p<0.001)$ but explains only 28 percent of the variance in informal learning from colleagues and supervisors, compared to the 37 percent variance explained by the main model, shown in Figure 3.

\section{<Insert Figure 4 about here>}

\section{Additional analysis distinguishing positive and critical feedback as separate mediators}

Following, for instance, Morran and Stockton (1980), Steelman et al. (2004) and Nelen and De Grip (2009), we perform an additional analysis, distinguishing positive and critical feedback as separate mediators. Although confirmatory factor analyses and Cronbach's alpha suggest that the

four items we use to measure feedback form one construct, ${ }^{\text {vii }}$ separate constructs for positive and critical feedback also result in good factor loadings and Cronbach alphas. ${ }^{\text {viii }}$

Figure 5 shows the results of this additional analysis, again using the Preacher-Hayes (2008) method and the same controls. As in our main model, the NWW facet access to organizational knowledge is the only facet with a strong significant total effect $(\beta=0.12)$ on informal learning and this effect decreases only modestly when accounting for mediation $(\beta=$ 0.09). Furthermore, we see a weakly significant positive relation between the facet flexibility in working relations and informal learning $(\beta=0.07)$ that is fully mediated by the combination of positive and critical feedback. Moreover, we can now see a significant positive relation between access to organizational knowledge and the mediator positive feedback $(\beta=0.12)$ and between 
flexibility in working relations and the mediators positive feedback $(\beta=0.15)$ and critical feedback $(\beta=0.08)$. Also the facet freely accessible open workplace $(\beta=0.13)$ has a significant positive relation with the mediator positive feedback. The facet management of output $(\beta=-$ 0.10) has a significant negative relation with the mediator critical feedback. Finally, Figure 5 shows that both positive feedback $(\beta=0.09)$ and critical feedback $(\beta=0.19)$ are significantly positive related to informal learning.

However, whereas the facets access to organizational knowledge, flexibility in working relations, and a freely accessible open workplace showed significant indirect effects on informal learning in our main model (Figure 3), we see here only an indirect effect for the facet management of output $(\beta=-0.02)$, which runs via critical feedback. The total model is again highly significant $(p<0.001)$ and explains 38 percent of the variance in informal learning. The effects of our control variables are the same as in the previous models.

<Insert Figure 5 about here>

\section{Discussion}

The main goal of this first study on the relation between NWW and informal learning is to provide the first empirical evidence on this relation and to provide stepping-stones for future research to build on. To do so, we have first investigated the relation between NWW as one bundled variable and a broad definition of informal learning. Controlling for a range of proven antecedents of informal learning, we find that NWW, as a bundle of practices, is positively related to the informal learning of employees. This relation is fully mediated by the frequency with which employees receive feedback. 
Next, we dug deeper with additional analyses of the relations between on the one hand the five individual NWW facets and on the other hand informal learning broadly defined, as well as specifically focusing on learning from colleagues and supervisors (i.e. excluding learning by doing). Our subsequent analysis, which focuses on the five separate facets of NWW, reveals that access to organizational knowledge is the only NWW facet that positively relates to informal learning. This effect is only marginally mediated by the frequency of receiving feedback. The facet flexibility in working relations is positively related to informal learning, albeit only weakly significant. This weak relation is fully mediated by the frequency of receiving feedback. The facets time- and location-independent work, management of output, and a freely accessible open workplace are not significantly related to informal learning. The only significant indirect effects on informal learning via the frequency of receiving feedback are from the facets access to organizational knowledge, flexibility in working relations, and a freely accessible open workplace.

Additional analysis on learning from colleagues and supervisors shows that the facet management of output relates negatively and the facet access to organizational knowledge relates positively to this kind of informal learning when the mediating effect of the frequency of receiving feedback is included.

Additional analysis also shows that critical feedback is much more strongly related to informal learning, compared to positive feedback. Following this, the mediating effect of the frequency of receiving feedback on informal learning mostly runs via critical feedback and less so via positive feedback. 


\section{Theoretical contributions}

Our study contributes to both the literature on NWW and the literature on (the antecedents of) informal learning in the workplace by showing that NWW, as a bundle of HRM practices, will increase informal learning at work, whereby access to organizational knowledge appears to be an independent driver of informal learning in the broad sense, and that management of output appears to restrict informal learning from colleagues and supervisors. These results have been obtained while controlling for several other antecedents of informal learning, such as recent formal training participation, percentage of time performing teamwork, and organizational learning support, showing the independent impact of these NWW facets on informal learning. In addition, we show that the frequency with which employees receive feedback fully mediates the effect of NWW when considered as a bundle of HRM practices, and that feedback only partially mediates the relation between the facets access to organizational knowledge and management of output. This mediating effect mostly runs via critical feedback and less so via positive feedback.

Similarly, we add to the emerging literature on the effects of NWW on employee outcomes such as work engagement (Ten Brummelhuis et al., 2012; Gerards et al., 2018), employee performance (De Leede and Kraijenbrink, 2014), work-related flow (Peters et al., 2014), and productivity and organizational commitment (De Leede and Heuver, 2017), by showing that NWW, as a bundle, are positively related to informal learning. Our findings that access to organizational knowledge and management of output directly affect respectively informal learning and informal learning from colleagues and supervisors, whereas the indirect effects that run via feedback are relatively small, suggest that the effects of these NWW facets on informal learning are largely a direct process, with only modest mediating mechanisms. 
Moreover, several of our findings are relevant to the teleworking literature. The negative relation we observe for the NWW facet management of output — which is a key component of what is also known in the literature as teleworking — and critical feedback is in line with most of the empirical evidence which also points toward this negative relation (e.g. Sardeshmukh et al., 2012; Boell et al., 2016). The absence of any strong significant relation of the NWW facet timeand location-independent work - another key component of what is known as teleworking — with feedback lends support to the recent empirical evidence of Caillier (2013), who finds no effect of teleworking on receiving feedback at work. However, the positive relation we find between the NWW facet access to organizational knowledge — also a key component of teleworking — and feedback differs from the aforementioned empirical studies.

In addition, the relations we observe between, on the one hand, the various NWW facets and, other the other hand, the Feedback Environment Scale (FES) facets frequencies of receiving positive and critical feedback (Steelman et al., 2004), contribute to the literature on the feedback environment - where the antecedents of the feedback environment are understudied (Dahling $e t$ al., 2017) —with empirical evidence on new antecedents of these two important facets of the feedback environment.

Lastly, the positive effect of the NWW facet access to organizational knowledge on informal learning, which we predicted based on the Job Demand-Control model and the Job Demands-Resources model, and the negative effect of management of output on informal learning from colleagues and supervisors, which likely occurs because this facet also reduces the frequency of receiving critical feedback, add several pieces to the thus far inconclusive evidence on the effects of teleworking on informal learning. For instance, Cooper and Kurland (2002) and Kurland and Bailey (1999) find a negative relation between teleworking and informal learning, whereas De Leede and Kraijenbrink (2014) find a positive relation, and Boell et al. (2016) 
conclude that empirical findings concerning telework are often paradoxical. However, by analyzing the individual components of NWW (and, with those, teleworking) as well as two different measures of informal learning, we find there are both positive (access to organizational knowledge) and negative (management of output) effects of certain NWW facets on informal learning (from colleagues and supervisors). This shows that what would have seemed paradoxical based on analyses using aggregate measures of NWW and informal learning can be explained by looking at more specific components of NWW or teleworking and informal learning.

\section{Practical implications}

Rarely, if ever, is the promotion of informal learning regarded as one of the reasons why organizations advocate or implement NWW. Although we find that NWW, as a bundle, will increase informal learning at work, our findings also show that not all NWW facets increase informal learning. Whereas introducing access to organizational knowledge appears to be a driver of informal learning, management of output seems to decrease informal learning specifically from colleagues and supervisors. These findings are of interest for human resource and general managers seeking new ways to stimulate informal learning. Since information and communication technologies offer ample opportunities for giving employees access to organizational knowledge, organizations should take these opportunities to foster informal learning at work. However, when management of output is the current practice, organizations should remain alert, since, when the output itself is apparently paramount, opportunities for informal learning from colleagues and supervisors as well as the frequency of critical feedback could be reduced by this management style. 


\section{Limitations and future research}

Since our data are cross-sectional we cannot identify causal relations. Furthermore, the external validity of our findings for countries beyond the Netherlands may be restricted, due to differences in culture between working populations of different countries. Therefore, longitudinal and crosscountry studies of the effects of NWW form an interesting avenue for further research. This could also allow the distinction between employees already accustomed to NWW and those who are still relatively new to it. Future research in the field of NWW should also aim to obtain more insight into the extent to which informal learning mediates the positive effects of NWW on employee performance, work engagement, work-related flow, productivity, and organizational commitment, as found in other studies on NWW. 


\section{References}

Allen, T. D., Golden, T. D. and Shockley, K. M. (2015), "How effective is telecommuting? Assessing the status of our scientific findings", Psychological Science in the Public Interest, Vol. 16 No. 2, pp. 40-68.

Anseel, F., Beatty, A. S., Shen, W., Lievens, F. and Sackett, P. R. (2015), "How are we doing after 30 years? A meta-analytic review of the antecedents and outcomes of feedbackseeking behavior", Journal of Management, Vol. 41 No. 1, pp. 318-348.

Bakker, A. B. and Demerouti, E. (2007), “The job demands-resources model: State of the Art", Journal of Managerial Psychology, Vol. 22 No. 3, pp. 309-328.

Bell, B. S., Tannenbaum, S. I., Ford, J. K., Noe, R. A., and Kraiger, K. (2017), “100 years of training and development research: What we know and where we should go", Journal of Applied Psychology, Vol. 102 No. 3, pp. 305-323.

Blok, M. M., Groenesteijn, L., Schelvis, R. and Vink, P. (2012), “New ways of working: does flexibility in time and location of work change work behavior and affect business outcomes?", Work, Vol 41 No. 1, pp. 2605-2610.

Boell, S. K., Cecez-Kecmanovic, D. and Campbell, J. (2016), “Telework paradoxes and practices: the importance of the nature of work", New Technology, Work and Employment, Vol. 31 No. 2, pp. 114-131.

Bond, F. W., and Flaxman, P. E. (2006), "The ability of psychological flexibility and job control to predict learning, job performance, and mental health", Journal of Organizational Behavior Management, Vol. 26 No. 1-2, pp. 113-130.

Branine, M. (2003), "Part-time work and jobsharing in health care: is the NHS a family-friendly employer?", Journal of Health Organization and Management, Vol. 17 No. 1, pp. 53-68. 
Caillier, J. G. (2013), "Does teleworking affect managing for results and constructive feedback? A research note", Canadian Public Administration, Vol. 56 No. 4, pp. 638-654.

Cerasoli, C. P., Alliger, G. M., Donsbach, J. S., Mathieu, J. E., Tannenbaum, S. I. and Orvis, K.A. (2018), “Antecedents and Outcomes of Informal Learning Behaviors: a MetaAnalysis", Journal of Business and Psychology, Vol. 33 No. 2, pp. 203-230.

Clardy, A. (2018), "70-20-10 and the Dominance of Informal Learning: A Fact in Search of Evidence", Human Resource Development Review, Vol. 17 No. 2, pp. 153-178.

Cooper, C. D. and Kurland, N. B. (2002), “Telecommuting, professional isolation, and employee development in public and private organizations", Journal of Organizational Behavior, Vol. 23 No. 4, pp. 511-532.

Dahling, J.J., Gabriel, A.S. and MacGowan, R. (2017), “Understanding typologies of feedback environment perceptions: A latent profile investigation", Journal of Vocational Behavior, Vol. 101, pp. 133-148.

De Grip, A. (2015), "The importance of informal learning at work", IZA World of Labor, Vol. 162, pp. 1-10. doi: 10.15185/izawol.162

De Grip, A., Sauermann, J. and Sieben, I. (2016), “The Role of Peers in Estimating TenurePerformance Profiles: Evidence from Personnel Data", Journal of Economic Behavior \& Organization, Vol. 126 Part A, pp. 39-54.

De Lange, A. H., Taris, T. W., Kompier, M. A., Houtman, I. L., and Bongers, P. M. (2003), “ "The very best of the millennium": longitudinal research and the demand-control(support) model”, Journal of occupational health psychology, Vol. 8 No. 4, pp. 282-305.

De Leede, J. and Heuver, P. (2017), "New Ways of Working and Leadership: An Empirical Study in the Service Industry", in De Leede, J. (Ed.), New Ways of Working Practices: Antecedents and Outcomes, Emerald Group Publishing Limited, Bingley, pp. 49-71. 
De Leede, J. and Kraijenbrink, J. (2014), “The Mediating Role of Trust and Social Cohesion in the Effects of New Ways of Working: A Dutch Case Study”, in Bondarouk, T. and Olivas-Luján, M.R. (Eds), Human Resource Management, Social Innovation and Technology, Advanced Series in Management, Emerald Group Publishing Limited, Bingley, Vol. 14, pp. 3-20.

De Leede, J., Looise, J. K. and Riemsdijk, M. (2004), “Collectivism versus individualism in Dutch employment relations", Human Resource Management Journal, Vol. 14 No. 1, pp. 25-39.

Eraut, M. (2004), "Informal learning in the workplace”, Studies in Continuing Education, Vol. 26 No. 2, pp. 247-273.

Fonner, K. L. and Roloff, M. E. (2010), "Why teleworkers are more satisfied with their jobs than are office-based workers: When less contact is beneficial", Journal of Applied Communication Research, Vol. 38 No. 4, pp. 336-361.

Fuchs, C. and Diamantopoulos, A. (2009), "Using single-item measures for construct measurement in management research: Conceptual issues and application guidelines”, Die Betriebswirtschaft, Vol. 69 No. 2, pp. 195-210.

Gagné, M., Forest, J., Vansteenkiste, M., Crevier-Braud, L., Van den Broeck, A. and Aspeli, A.K., (2015), “The Multidimensional Work Motivation Scale: Validation evidence in seven languages and nine countries", European Journal of Work and Organizational Psychology, Vol. 24 No. 2, pp. 178-196.

Gerards, R., De Grip, A. and Baudewijns, C. (2018), "Do New Ways of Working increase work engagement?", Personnel Review, Vol. 47 No. 2, pp. 517-534.

Gerstner, C. R. and Day, D. V. (1997), "Meta-Analytic review of leader-member exchange theory: Correlates and construct issues", Journal of Applied Psychology, Vol. 82 No. 6, 
pp. 827-844.

Karasek Jr, R. A. (1979), “Job demands, job decision latitude, and mental strain: Implications for job redesign", Administrative science quarterly, Vol. 24 No. 2, pp. 285-308.

Karasek, R. and Theorell, T. (1990). Healthy work: Stress, productivity and the reconstruction of working life. New York: Basic Books.

Kossek, E. E. and Lee, M. D. (2008), “Implementing a reduced-workload arrangement to retain high talent: A case study", The Psychologist-Manager Journal, Vol. 11 No. 1, pp. 49-64.

Kyndt, E., Dochy, F. and Nijs, H. (2009), "Learning conditions for non-formal and informal workplace learning”, Journal of Workplace Learning, Vol. 21 No. 5, 369-383.

Kurland, N. B. and Bailey, D. E. (1999), "When workers are here, there, and everywhere: A discussion of the advantages and challenges of telework", Organizational Dynamics, Vol. 28 No. 2, pp. 53-58.

Laursen, K. and Foss, N. J. (2003), "New human resource management practices, complementarities and the impact on innovation performance", Cambridge Journal of Economics, Vol. 27 No. 2, pp. 243-263.

Laursen, K. and Mahnke, V. (2001), "Knowledge strategies, firm types, and complementarity in human-resource practices”, Journal of Management and Governance, Vol. 5 No. 1, pp. 127.

Marsick, V. J. and Watkins, K. E. (2001), “Informal and incidental learning”, New directions for adult and continuing education, Vol. 2001 No. 89, pp. 25-34.

McCauley, C. D., Ruderman, M. N., Ohlott, P. J., and Morrow, J. E. (1994), “Assessing the developmental components of managerial jobs", Journal of applied psychology, Vol. 79 No. 4, pp. 544-560.

Morran, K. and Stockton, R. (1980), "Effect of self-concept and group member reception of 
positive and negative feedback”, Journal of Counseling Psychology, Vol. 27 No. 3, pp. $260-267$.

Mulder, R. (2013), "Exploring feedback incidents, their characteristics and the informal learning activities that emanate from them", European Journal of Training and Development, Vol. 37 No. 1, pp. 49-71.

Nelen, A. and De Grip, A. (2009), "Why Do Part-time Workers Invest Less in Human Capital than Full-timers?", Labour, Vol. 23 No. 1, pp. 61-83.

Noe, R. A., Tews, M. J. and Marand, A. D. (2013), "Individual differences and informal learning in the workplace", Journal of Vocational Behavior, Vol. 83 No. 3, pp. 327-335.

OECD (2014). “Technical Report of the Survey of Adult Skills, Reader's Companion”, Paris: OECD Publishing.

Oldham, G. R. and Brass, D. J. (1979), "Employee reactions to an open-plan office: A naturally occurring quasi-experiment”, Administrative Science Quarterly, Vol. 24 No. 2, pp. 267284.

Pejtersen, J., Allermann, L., Kristensen, T. S. and Poulsen, O. M. (2006), “Indoor climate, psychosocial work environment and symptoms in open-plan offices”, Indoor Air, Vol. 16 No. 5, pp. 392-401.

Peters, P., Poutsma, E., Van der Heijden, B. I., Bakker, A. B. and Bruijn, T. D. (2014), “Enjoying New Ways to Work: An HRM-Process Approach to Study Flow”, Human Resource Management, Vol. 53 No. 2, pp. 271-290.

Preacher, K. J. and Hayes, A. F. (2008), “Asymptotic and resampling strategies for assessing and comparing indirect effects in multiple mediator models", Behavior Research Methods, Vol. 40 No. 3, pp. 879-891. 
Preenen, P. T., De Pater, I. E., Van Vianen, A. E., and Keijzer, L. (2011), "Managing voluntary turnover through challenging assignments", Group \& Organization Management, Vol. 36 No. 3, pp. 308-344.

Sardeshmukh, S. R., Sharma, D. and Golden, T. D. (2012), "Impact of telework on exhaustion and job engagement: A job demands and job resources model", New Technology, Work and Employment, Vol. 27 No. 3, pp. 193-207.

Schürmann, E. and Beausaert, S. (2016), “What are drivers for informal learning?”, European Journal of Training and Development, Vol. 40 No. 3, pp. 130-154.

Spector, P. E., and Brannick, M. T. (2011), "Methodological urban legends: The misuse of statistical control variables", Organizational Research Methods, Vol. 14 No. 2, pp. 287305.

Steelman, L. A., Levy, P. E. and Snell, A. F. (2004), “The feedback environment scale: Construct definition, measurement, and validation", Educational and Psychological Measurement, Vol. 64 No. 1, pp. 165-184.

Ten Brummelhuis, L. L., Bakker, A. B., Hetland, J. and Keulemans, L. (2012), "Do new ways of working foster work engagement?", Psicothema, Vol. 24 No. 1, pp. 113-120.

Tews, M. J., Michel, J. W. and Noe, R. A. (2017), "Does fun promote learning? The relationship between fun in the workplace and informal learning", Journal of Vocational Behavior, Vol. 98, pp. 46-55.

Van der Doef, M., and Maes, S. (1999), “The job demand-control (-support) model and psychological well-being: a review of 20 years of empirical research", Work \& stress, Vol. 13 No. 2, pp. 87-114.

Van Ruysseveldt, J. and Van Dijke, M. (2011), "When are workload and workplace learning opportunities related in a curvilinear manner? The moderating role of autonomy", Journal 
of Vocational Behavior, Vol. 79 No. 2, pp. 470-483. 
Table I. Internal consistencies and correlations between the variables

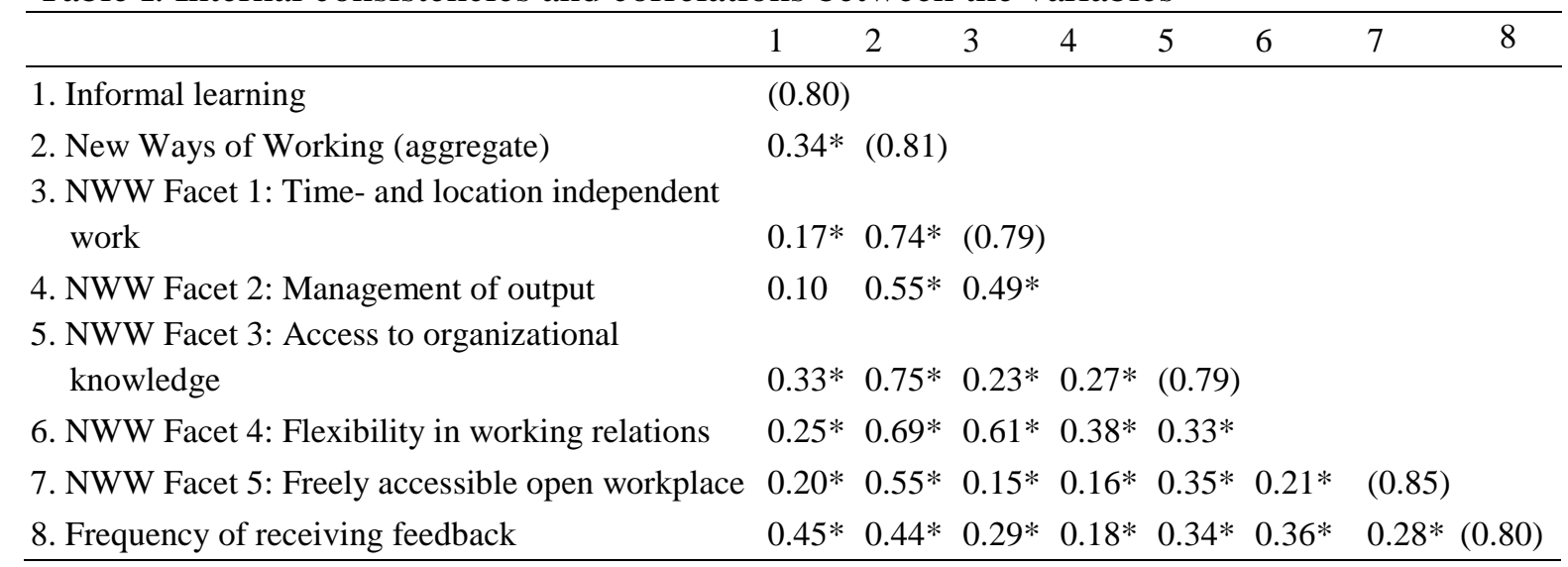

Notes: $n=642$. Cronbach's $\alpha$ coefficients are shown in the diagonal. * Significant at $\mathrm{P}<.001$ 
Figure 1. Overview of our hypothesized relationship between NWW and informal learning.

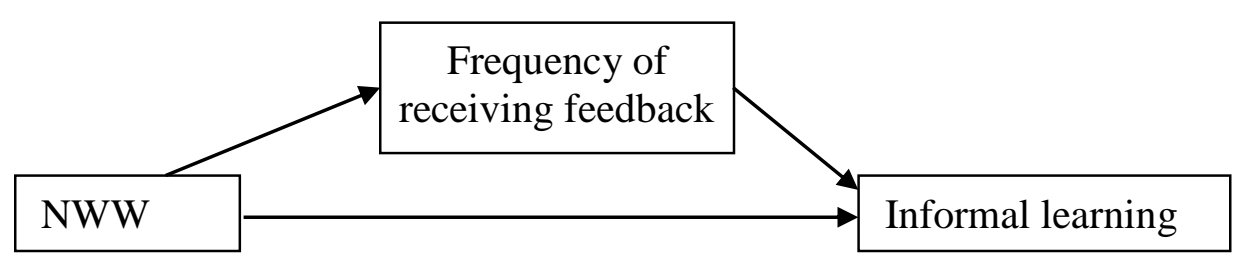

Figure 2. Mediation model of direct and indirect effects of NWW on informal learning.

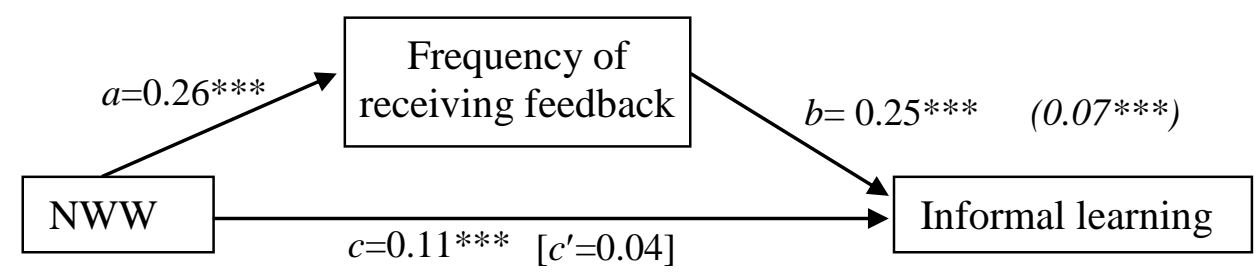

Notes:

- Indirect effect $\left(a^{*} b\right)$ is shown in italics in parentheses. Direct effect of NWW accounting for mediation is shown in brackets.

- $\quad * * * p<0.01, * * p<0.05, * p<0.10$

- $\quad$ Total effect $c=a * b+c^{\prime}$ 
Figure 3. Mediation model of direct and indirect effects of individual facets of NWW on informal learning, via the frequency of receiving feedback.

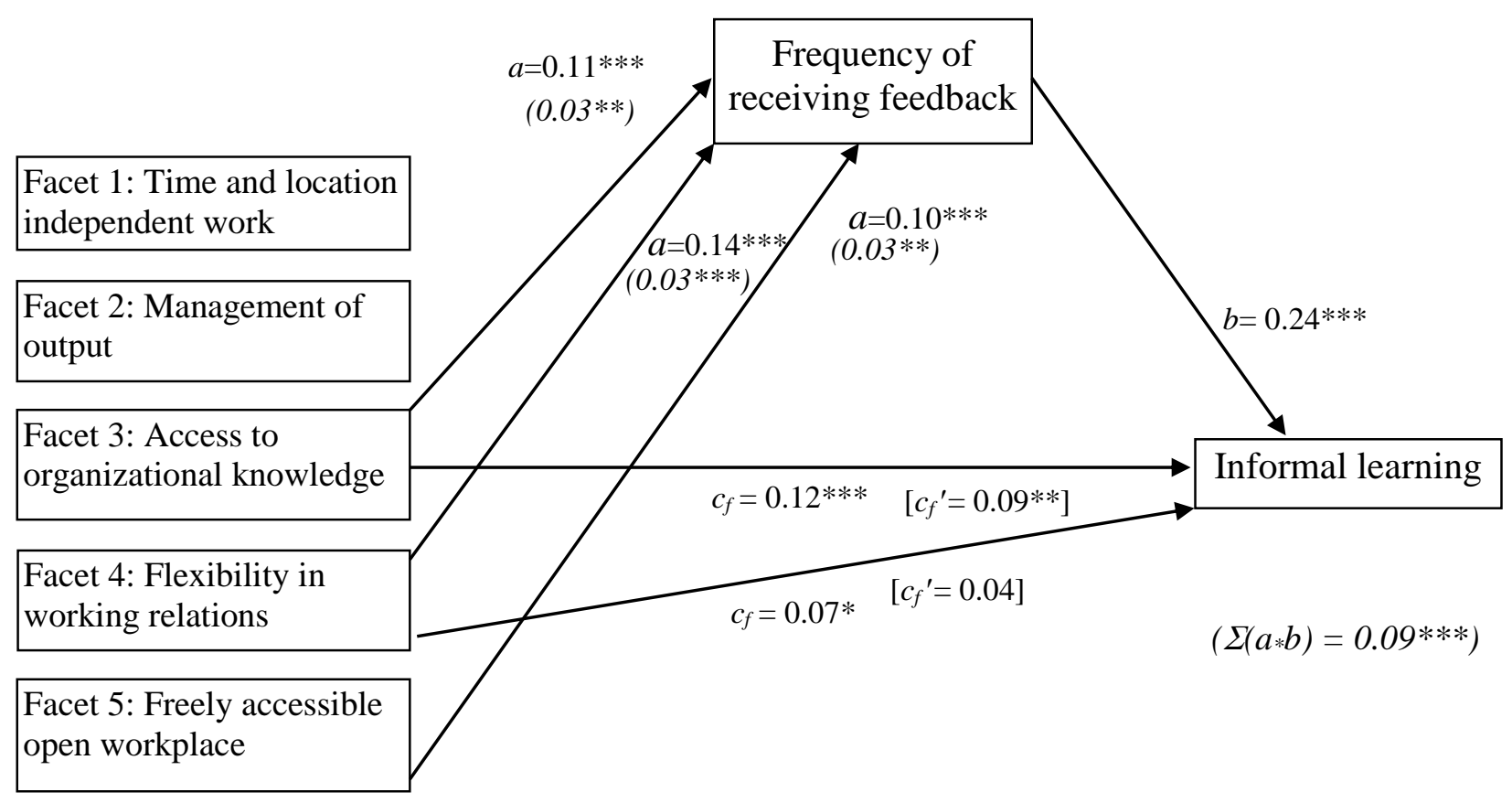

Notes:

- Indirect effects $(a * b)$ and total indirect effect $\left(\Sigma\left(a^{*} b\right)\right)$ are shown in italics in parentheses. Direct effects of NWW facets accounting for mediation are shown in brackets.

- We only show significant relations. $* * * p<0.01$, ** $p<0.05, * p<0.10$

- Total effect per facet ' $\mathrm{f}$ ' is $c_{\mathrm{f}}=\Sigma\left(a_{\mathrm{f}} \mathrm{f}^{*} b\right)+c_{\mathrm{f}}$ ' 
Figure 4. Mediation model of direct and indirect effects of individual facets of NWW on informal learning from colleagues and supervisors, via the frequency of receiving feedback.

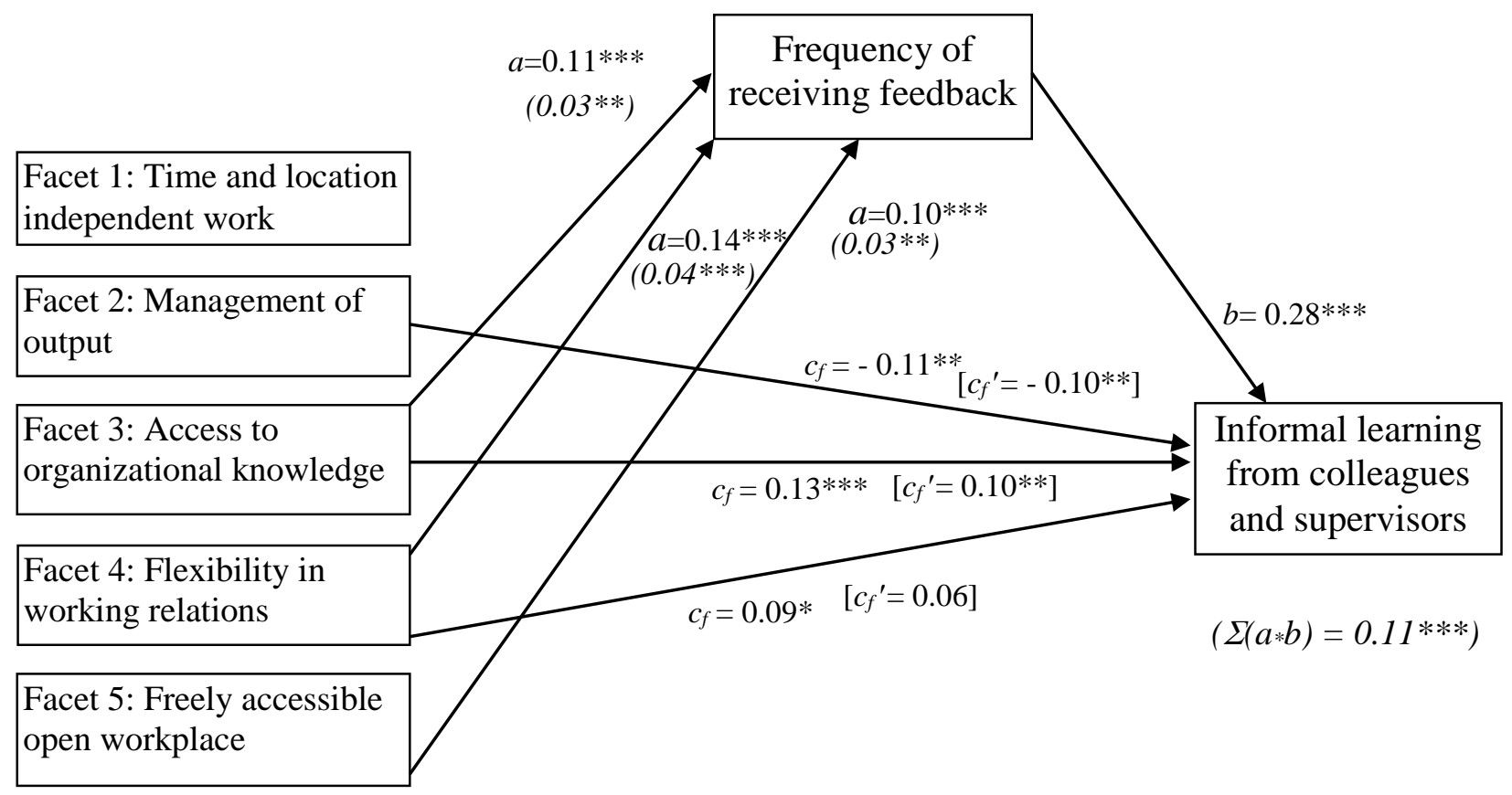

Notes:

- Indirect effects $(a * b)$ and total indirect effect $\left(\Sigma\left(a^{*} b\right)\right)$ are shown in italics in parentheses. Direct effects of NWW facets accounting for mediation are shown in brackets.

- We only show significant relations. $* * * p<0.01$, ** $p<0.05, * p<0.10$

- Total effect per facet ' $\mathrm{f}$ ' is $c_{\mathrm{f}}=\Sigma\left(a_{\mathrm{f}, *} b\right)+c_{\mathrm{f}}$ ' 
Figure 5. Multiple mediation model of direct and indirect effects of individual facets of NWW on informal learning, via the frequency of receiving positive and critical feedback.

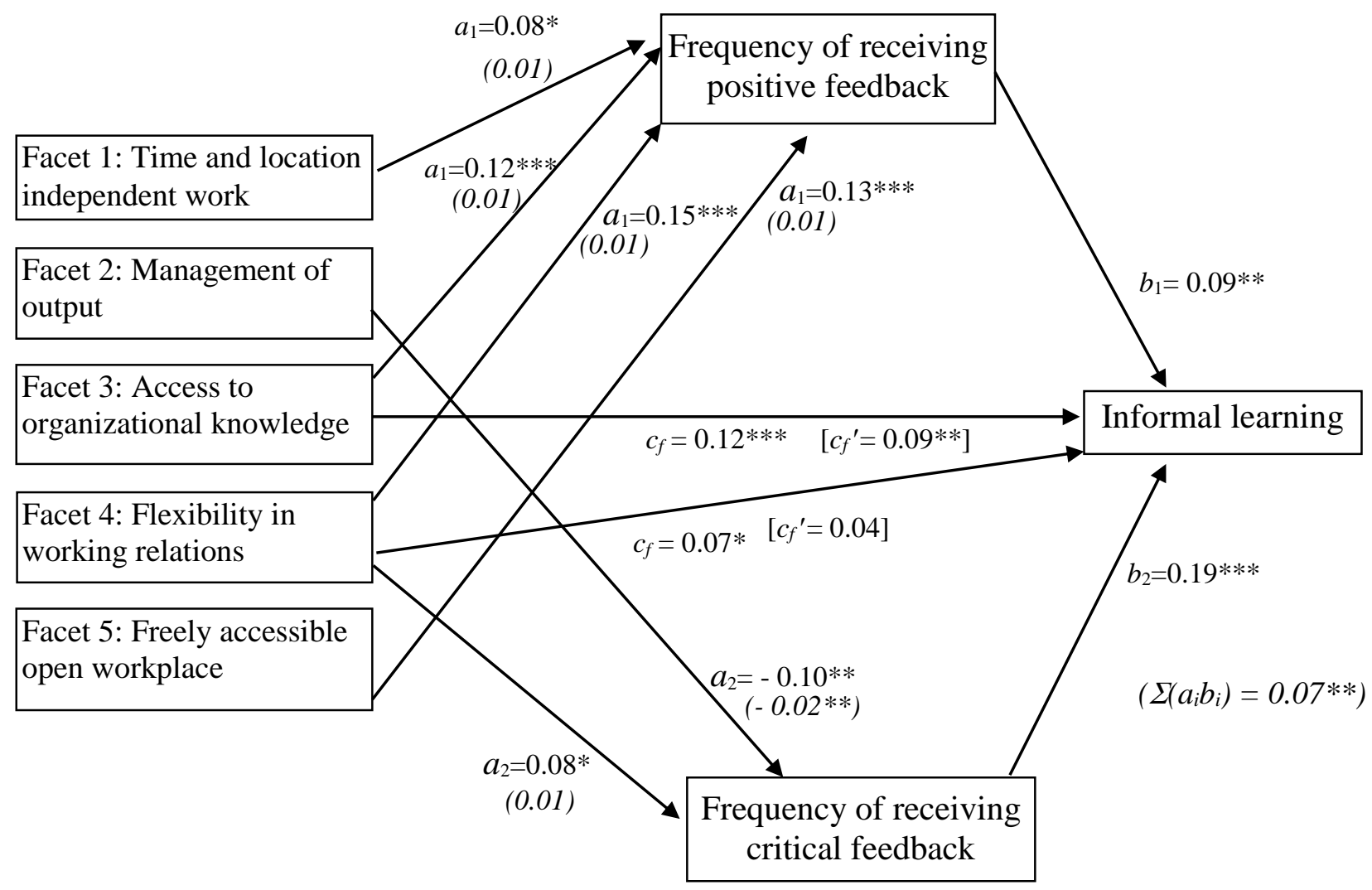

Notes:

- Indirect effects $\left(a_{\mathrm{i}} b_{\mathrm{i}}\right)$ and total indirect effect $\left(\Sigma\left(a_{\mathrm{i}} b_{\mathrm{i}}\right)\right)$ are shown in italics in parentheses. Direct effects of NWW facets accounting for mediation are shown in brackets.

- We only show significant relations. ${ }^{* * *} p<0.01$, ** $p<0.05, * p<0.10$

Total effect per facet ' $\mathrm{f}$ ' is $c_{\mathrm{f}}=\Sigma\left(a_{\mathrm{i}, \mathrm{f} *} b_{\mathrm{i}}\right)+c_{\mathrm{f}}$ '

\footnotetext{
${ }^{\text {i }}$ See http://www.etil.nl.

ii Contrary to what the follow up nature of the survey may suggest, we are unable to exploit this as panel data as we do not know whether individual respondents were in the same job at both moments of time.

iii See Gerards et al. (2018) for a full list of items.

iv The facets management of output and flexibility in working relations are single-item facets. Based on the criteria of Fuchs and Diamantopoulos (2009), Gerards et al. (2018) conclude that using single item measures is justifiable here, since these facets are relatively concrete and unidimensional and the sampled population is very diverse.

${ }^{v}$ Across all these factor analyses, the lowest factor loading we observe is 0.54 and the highest is 0.87 . The results are available from the authors upon request.

${ }^{v i}$ We have omitted the corresponding bootstrap results for all our analyses for reasons of brevity, but they have been reviewed and are available from the authors upon request.
} 
vii Only one eigenvalue is above one, there are strong factor loadings (between 0.72 and 0.78 ) on only one factor, and Cronbach alpha is 0.80 .

viii Only one eigenvalue is above one and there are factor loadings of 0.79 and a Cronbach alpha of 0.81 for positive feedback; only one eigenvalue is above one and there are factor loadings of 0.74 and a Cronbach alpha of 0.76 for critical feedback. 